\title{
WEATHER IMPACTS, FORECASTS, AND POLICY An Integrated Perspective
}

\author{
by Roger Pielke Jr. and R. E. Carbone
}

\begin{abstract}
Weather research is unlikely to more effectively meet society's needs - or receive greater resources - if the community proceeds in balkanized fashion; integration is an imperative.
\end{abstract}

S ociety invests considerable resources into the science and technology of weather services. By some estimates, public and private direct expenditure for the provision of weather forecasting totals more than approximately $\$ 5$ billion annually (Hooke and Pielke 2000). ${ }^{1}$ Public sector investment in operations, observational and computational infrastructure, and research and development compose the majority of this total. However the private sector is rapidly developing, with estimates of the market for weather services approaching \$1 billion [United States Weather Research Program (USWRP) 2001]. Another type of estimate suggests that approximately $\$ 1$ trillion of the nation's $\$ 7$ trillion economy is weather sensitive [e.g., National Research Council (NRC) 1998]. But as interesting as these numbers might be, what do they say about the appropriate level of investment by society-in the public and private sectorsfor weather services? The answer is "not much."

Affiliations: Pielke JR. AND CARbone-National Center for Atmospheric Research, Boulder, Colorado (The National Center for Atmospheric Research is sponsored by the National Science Foundation)

CORRESPONDING AUTHOR: Roger Pielke Jr., Environmental and Societal Impacts Group, NCAR, P.O. Box 3000, Boulder, CO 80307-3000

E-mail: rogerp@ucar.edu

In final form 20 June 2001

@2002 American Meteorological Society
In order to effectively assess the market for weather services, and thus properly scale the level of resources that, for example, the U.S. Congress or a company ought to devote to serving this market, decision makers need information on the costs and benefits associated with alternative courses of action (cf. Pielke and Glantz 1995). To date such information has not been readily or systematically available, raising questions about the effectiveness of investment in the science and technology of weather (Emanuel et al. 1995; Pielke et al. 1997; NRC 1999). On the one hand, there are those engaged in research, development, and operations that argue the nation is underinvesting in weather, thus leading to missed opportunities and benefits as yet unrealized. On the other hand, there are those responsible for resource allocation decisions that cast a skeptical eye on the claims of opportunities and benefits, and note the not insubstantial ongoing investments into weather. The sidebar on page 394 provides examples of the sorts of questions that might be raised by such skeptics. The result is a standoff. Decisions about investment are made largely in the absence of information about the relative worth of alternative courses of action, and are thus subject

\footnotetext{
${ }^{1}$ Weather forecasting is a subset of weather services more broadly defined. This paper focuses on weather prediction, but we would suggest that the issues raised in the paper have potentially broader applicability to weather (and climate) services more generally, but this application goes well beyond the present focus.
} 
to political tinkering and ad hoc, piecemeal decisions-what Hooke and Pielke (2000) have called "an orchestra without a conductor."

We argue that the allocation of resources to weather in the public and private sectors is unlikely to become more effective-and of particular concern to the weather community, to grow significantlyunless the weather community takes an integrated perspective on weather impacts, forecasts, and policy that provides decision makers with reliable information on the costs and benefits of alternative courses of action. This paper suggests one such integrated perspective that might guide the provision of such information to decision makers.
IMPACTS OF WEATHER-IMPACTS OF

FORECASTS. It is well understood that to have value, information must be relevant in some fashion to a specific decision (Katz and Murphy 1997). Value results from making a decision (or decisions) that results in outcomes with greater benefits (less losses) than would a different decision (or decisions). The calculation of cost and benefits associated with alternative future courses of action are a form of prediction, subject to the same sort of uncertainties, reliance on assumptions, and judgement errors that characterize other types of prediction (Sarewitz et al. 2000). It is therefore important to routinely evaluate the "goodness" of such cost and benefit projections ret-

\section{SIX HERETICAL NOTIONS ABOUT WEATHER POLICY}

Six heretical notions about weather policy, excerpted from WeatherZine, issue 21 , http:// sciencepolicy.colorado.edu/ zine/archives/ I-29/2 I/ editorial.html. How would you respond to these hypothetical issues that might be raised by a public official?

I) The atmospheric sciences collect more data than is used or can be used in either research or operations. When field programs or satellites are funded, subsequent analysis often is not. This circumstance makes it difficult for people outside the community (and indeed some inside) to understand why more data is needed, and what its ultimate value is in terms of improvements in forecasts as well as opportunities foregone.

2) Many claim that the forecasts in the United States are the best in the world. At the same time, some people claim that the Europeans have passed us by. Some who say that the United States is keeping pace with the Europeans argue that we have done so because of innovative use of observations (via creative data assimilation techniques and use of scarce computer time). This is tantamount to saying that funding limitations have motivated extra value from existing resources. The bottom line: Do we really know how "good" forecasts have to be, and at what cost?

3) In any case, public funding for the atmospheric sciences is truly enormous-approximately $\$ 2-3$ billion is spent on weather and climate research and operations each. When the weather community says that forecasts could improve but only for a small budget increase, one might expect a policy maker to reply: "Great, you should be able to handle that with existing expenditures!"

4) Much more research is produced than is used, or can be used, in the operational forecast process. Much is "left on the floor." The connections between research and the use of research in operations, and ultimately to benefits to decision makers is poorly understood. Until the community can link a request for more resources with expected effects on forecasts and ultimately benefits, securing significant additional funding will be difficult.

5) In any case, improved use and value is in many instances constrained by dated products and a lack of understanding of the needs of users. In 1997 in Grand Forks, North Dakota, a technically accurate forecast was misinterpreted and misused because neither forecasters nor local decision makers understood what it meant. Scientific and technological advances mean little if they are not well incorporated into decision making.

6) The weather community is so large and full of overlaps and redundancies that no one really knows what the universe looks like. It is difficult for the weather community to speak with one voice, but at a minimum there should be some knowledge of the whole. And there is the destructive public-private debate over roles and responsibilities. Obtaining such knowledge and resolving this debate would greatly enhance credibility when a case is made for more support from the public. 
rospectively, for example, against actual experience (e.g., Stewart 1997). But whether looking forward or back, in theory or in practice, all measures of costs and benefits of weather services have their origins in the knowledge of the impacts of weather and of weather forecasts.

The quantitative assessment of the impacts on society of weather and climate extremes is challenging. There is no centralized collection of data and no standardized methodology. (The H. John Heinz III Center for Science, Economics and Environment 1999; NRC, Committee on Assessing the Costs of Natural Disasters 1999). Thus, any assessment must pay attention to at least three factors: 1) how impacts are measured, 2) what is overlooked through reliance on available quantitative information, and 3) the interrelation of atmospheric and societal trends that condition temporal or spatial patterns in impacts.

The analyst's choice of the temporal and spatial scale of the impacts affects the assessment (Kunkel et al. 1999). Over different periods and areas one can arrive at different, but equally valid, measures of impacts. For instance, while a local community might experience devastating losses immediately following a weather disaster, at a regional or national scale there are those who might benefit over a longer period through such effects as increased commodity prices or an increased demand for building supplies. Direct impacts (i.e., economic or loss of life) that are immediately related to the event are generally the most easily measured. Second-order impacts (e.g., costs associated with providing freshwater and supplies) may be incurred days or weeks after the event. Higherorder impacts (e.g., loss of tourist revenue, change in tax revenues) may occur months or years later and are difficult to identify and quantify amid the normal variability of social processes.

Another factor is the difficulty in quantifying certain losses, such as human hardship or environmental damages. Measurable economic losses and casualties are not all that matters. And even in cases where the impact itself is quantifiable, disentangling the contribution of weather (or weather forecasts) can pose a significant challenge (Katz and Murphy 1997).

To accurately interpret economic losses or lives lost from weather events requires understanding of the causes of those events. Because societal impacts are a joint function of atmospheric events and human action, the analyst must take care to discern which combination of factors results in impacts (e.g., hurricane damage and airplane accidents are both often the result of both weather and poor decisions). Economic losses must be adjusted for inflation and other relevant changes such as population growth and increasing wealth in order to discern changes in climate or to assess the value of scientific information. In addition, casualty rates are influenced by factors such as population density, standards and styles of living, the changing nature of business and commerce, and improvements in forecasting and warning systems for severe weather events. Normalization methodologies have been employed in a number of contexts (but not all) to help disentangle the impacts record (e.g., Changnon et al. 2000).

The concept of weather impacts and weather forecast impacts include

- extreme events, including droughts, hurricanes, floods, blizzards, tornadoes, thunderstorms (including hail), etc.;

- the benefits of good weather, meaning favorable conditions for a particular activity;

- routinely disruptive weather, defined as not extreme, but significant enough to warrant behavioral adjustments; and

- forecast impacts, particular those associated with type I and type II errors, that is, misses and false alarms (including overwarning). Recent experiences with hurricane and winter storm forecasts along the U.S. east coast are highly visible examples of such impacts.

The following three sections briefly review each.

Extreme events. Because of their tremendous impact, researchers have devoted considerable attention to extreme weather impacts. Kunkel et al. (1999) review economic and other human losses related to extreme weather in the United States. Table 1 provides an update of their data, showing for the 1990s on the order of 900 deaths and $>\$ 13$ billion in losses annually. Caution is urged in the use of these aggregate figures. Different measures might arrive at smaller or larger results. For instance, the loss of life estimate neglects the 6000 or so people who lose their lives in weatherrelated traffic fatalities and the 50000 to 120000 premature deaths related to air pollution. ${ }^{2}$ Of the phenomena reported here, the largest loss of life in recent years has been associated with temperature extremes. ${ }^{3}$

\footnotetext{
${ }^{2}$ Weather-related traffic fatalities estimated from http:// www.nhtsa.dot.gov/people/ncsa/. Air pollution deaths from Centers for Disease Control, http://www.cdc.gov/nceh/ asthma/brochures/airpollu.htm.

${ }^{3}$ For more information see Mileti (1999) and the AMS/UCAR Extreme Weather Sourcebook 2001 Edition.
} 
TABLE I. Update of Kunkel et al. (1999).

\begin{tabular}{|c|c|c|c|c|}
\hline Event & $\begin{array}{l}\text { Annual mean } \\
\text { loss of life } \\
(19 x x-1989)\end{array}$ & $\begin{array}{c}\text { Annual mean loss } \\
\text { of life (1990s) }\end{array}$ & $\begin{array}{c}\text { Annual mean } \\
1999 \$ \text { loss } \\
(19 x x-1989)\end{array}$ & $\begin{array}{c}\text { Annual Mean 1999 \$ } \\
\text { loss (1990s) }\end{array}$ \\
\hline Floods & $\begin{array}{c}95^{\prime} \\
(1903-89)\end{array}$ & $\begin{array}{c}98^{\prime} \\
(1990-M a r 2000)\end{array}$ & $\begin{array}{c}\$ 1.8 B^{2} \\
(1903-89)\end{array}$ & $\begin{array}{c}\$ 5.3 B^{2} \\
(1990-99)\end{array}$ \\
\hline Hurricanes & $\begin{array}{c}173^{3} \\
(1900-89)\end{array}$ & $\begin{array}{c}21^{4} \\
(1990-2000)\end{array}$ & $\begin{array}{c}\$ 5 B^{5} \\
(1900-89)\end{array}$ & $\begin{array}{c}\$ 5.4 B * 5 \\
1990-2000)\end{array}$ \\
\hline Winter storms & & $\begin{array}{c}57^{6} \\
(1995-2 \text { Nov 2000) }\end{array}$ & & $\begin{array}{c}\$ 329 M^{* 6} \\
(1995-2 \text { Nov 2000) }\end{array}$ \\
\hline Tornadoes & $\begin{array}{c}97^{7} \\
(1950-89)\end{array}$ & $\begin{array}{c}56^{8} \\
(1990-2 \text { Nov 2000) }\end{array}$ & $\begin{array}{c}\$ 1.2 B^{9} \\
(1950-1989)\end{array}$ & $\begin{array}{l}\$ 777 M^{9} \\
(1990-99)\end{array}$ \\
\hline Extreme heat & $\begin{array}{c}412^{10} \\
(1979-89)\end{array}$ & $\begin{array}{c}282^{11} \\
(1990-98)\end{array}$ & & $\begin{array}{c}\$ 85 M^{* 12} \\
(1995-2 \text { Nov 2000) }\end{array}$ \\
\hline Extreme cold & $\begin{array}{c}393^{13} \\
(1979-89)\end{array}$ & $\begin{array}{c}292^{14} \\
(1990-98)\end{array}$ & & $\begin{array}{c}\$ 368 M * 15 \\
(1995-2 \text { Nov 2000) }\end{array}$ \\
\hline Lightning & $\begin{array}{c}88^{16} \\
(1979-89)\end{array}$ & $\begin{array}{c}69^{17} \\
(1990-98)\end{array}$ & & $\begin{array}{c}\$ 38 M^{* 18} \\
(1995-2 \text { Nov 2000) }\end{array}$ \\
\hline Hail & & $\begin{array}{c}\mathrm{I}^{18} \\
(1995-2 \text { Nov 2000) }\end{array}$ & & $\begin{array}{c}\$ 938 M^{*} \\
(1995-2 \text { Nov 2000) }\end{array}$ \\
\hline $\begin{array}{l}\text { Annual } \\
\text { averages }\end{array}$ & $\begin{array}{c}\mathbf{1 2 5 8} \\
\text { (not including winter } \\
\text { storms or hail) }\end{array}$ & 876 & & $>\$ 13 B$ \\
\hline \multicolumn{5}{|c|}{$* 2000$ damages are in unadjusted $2000 \$}$. \\
\hline
\end{tabular}

${ }^{1}$ Hydrologic Information Center, Flood Fatalities, www.nws.noaa.gov/oh/hic/flood_stats/recent_individual_deaths.html

${ }^{2}$ Hydrologic Information Center, Flood Losses, www.nws.noaa.gov/oh/hic/flood_stats/Flood_loss_time_series.htm

${ }^{3}$ Herbert et al. (1996).

${ }^{4}$ Herbert et al. (1996), for 1990-95; National Hurricane Center Preliminary Reports, (Bertha-www.nhc.noaa.gov/1996bertha.html; Franwww.nhc.noaa.gov/1996fran.html; Danny—www.nhc.noaa.gov/1997danny.html; Bonnie—www.nhc.noaa.gov/1998bonnie.html; Earl— www.nhc.noaa.gov/1998earl.html; Georges—www.nhc.noaa.gov/1998georges.html; Floyd—www.nhc.noaa.gov/1999floyd_text.html) for 1996-99; NWS Summary of 2000 Atlantic Hurricane Season, www.nhc.noaa.gov/text/MIATWSAT_nov.html, for 2000.

${ }^{5}$ Pielke et al. (2001).

${ }^{6}$ National Weather Service, Summary of U.S. Natural Hazard Statistics. For 1995-205.156.54.206/om/severe_weather/95sum.htm; for 1996-205.156.54.206/om/severe_weather/sum_96.htm; for 1997-205.156.54.206/om/severe_weather/sum97.htm; for 1998_ 205.156.54.206/om/severe_weather/sum98.pdf; for 1999-205.156.54.206/om/severe_weather/sum99.pdf; for 2000-205.156.54.206/om/ severe_weather/sum00.pdf.

${ }^{7}$ Storm Prediction Center, Tornadoes and Deaths by Year and Month, 1950-99, www.spc.noaa.gov/archive/tornadoes/ustdbmy.html

${ }^{8}$ Storm Prediction Center, Tornadoes and Deaths by Year and Month, 1950-99, www.spc.noaa.gov/archive/tornadoes/ustdbmy.html, for 1990-97; Storm Prediction Center, Monthly Tornado Statistics, www.spc.noaa.gov/climo/torn/monthlytornstats.html, for 1998-2000.

${ }^{9}$ Pielke et al. (2001), supra note 7.

${ }^{10}$ Parrish (1997).

${ }^{11}$ Parrish (1997), for 1990-94; Center for Disease Control Compressed Mortality Data, wonder.cdc.gov/mortsql.shtml for 1995-98.

${ }^{12}$ National Weather Service Summary of Natural Hazard Statistics, supra note 9.

${ }^{13}$ Parrish (1997).

${ }^{14}$ Parrish (1997), for 1990-94; Center for Disease Control Compressed Mortality Data, wonder.cdc.gov/mortsql.shtml for 1995-98.

${ }^{15}$ National Weather Service Summary of Natural Hazard Statistics, supra note 9.

${ }^{16}$ Parrish (1997).

${ }^{17}$ Parrish (1997), for 1990-94; Center for Disease Control Compressed Mortality Data, wonder.cdc.gov/mortsql.shtml for 1995-98.

${ }^{18}$ National Weather Service Summary of Natural Hazard Statistics, supra note 9. 
Good weather and routinely disruptive weather. By contrast, researchers pay considerably less attention to the benefits of good weather or the impacts of routinely disruptive weather. The report of a 1997 workshop on weather impacts concluded "the cumulative impacts of more typical day-to-day weather were significant, and probably much larger than the attention-getting extreme events" (USWRP 1997). Evidence for this assertion is scattered, but a good deal of the literature is summarized in Katz and Murphy (1997) and in an online resource on the Weather and Climate Forecast Use and Value Bibliography (online at http:// sciencepolicy.colorado.edu/biblio/index.html). Given the vast potential benefits associated with reducing the impacts of routinely disruptive weather or capitalizing on opportunities afforded by good weather, Katz and Murphy (1997) note that "somewhat surprisingly. .. relatively little attention has been paid to determining the economic benefits of existing weather forecasting systems or the incremental benefits of improvements in such systems." It is also worth noting that in recent years federal agencies have devoted considerable effort to understanding societal impacts related to seasonal and interannual climate (see, e.g., the Economics and Human Dimensions Program of the National Oceanic and Atmospheric Administration's Office of Global Programs online at http://www.ogp. noaa.gov/mpe/csi/econhd/index.htm, a subset of a broader program on Climate and Societal Interactions).

Forecast impacts. Forecasts themselves can have profound impacts. And given the reliance of society on weather (and increasingly climate) forecasts, the management of the impacts related to the use and misuse of forecasts will be increasingly important in the future (e.g., NRC 1998). An example illustrates the importance of forecast impacts.

In 1999, Hurricane Floyd attained the dubious distinction of being the first billion-dollar storm in which the costs of the evacuation rivaled the costs of the storm's impacts. Assuming for present purposes that the costs of evacuation are in the neighborhood of the oft-cited \$1 million per coastal mile, then the evacuation of about 2000 miles of coast related to Floyd's track along the U.S. east coast totaled $\$ 2$ billion. According to the insurance industry, insured losses associated with Floyd totaled more than $\$ 1$ billion, and flood costs add at least several billion to that.

In this extreme case of overwarning, this distinction between forecast impacts and weather impacts is significant because it dramatically reveals one of the hidden costs of hurricanes. Because forecasts are uncertain and liability looms large, much more coast- line must be warned than will actually experience a hurricane's impact. Consider that a hurricane typically directly affects about 100 miles of coast, and the average length of coastline warned per storm is 400 miles. This means that, on average, 300 miles of coast are warned but do not experience the direct effects of the hurricane (see Jarrell and Demaria 1999; Pielke 1999a). Floyd was obviously an extreme example of overwarning, but perhaps also an indication of the sorts of problems faced in the future as more and more people move to coastal locations.

A relative lack of surprises in the historical record is an indication of overwarning (Powell and Aberson 2001), that is, the assumption that it is better to warn and experience a miss than not warn and experience a hit. However, overwarning is not free. Again, assuming that the cost of overwarning is $\$ 1$ million per mile and that the average length of coastline warned per storm is 400 miles (after Jarrell and Demaria 1999) then the annual cost of this form of overwarning (a warned miss) can be computed as follows. Over the period 1976-2000 in the United States and its territories (in the Atlantic and Caribbean) hurricane warnings were issued for 12 hurricanes and tropical storms that did not strike, or an average of one every 2 years (Powell and Aberson 2001). Thus, one estimate of this form of overwarning is $\$ 200$ million per year:

(12 hurricanes)(400 miles)(\$1 million per mile)(24 yr).

For the mainland United States the figures are 7 storms and about $\$ 120$ million per year.

Furthermore, improved forecasts offer the promise of reducing the costs of overwarning by providing greater accuracy and reliability to emergency management officials who must make difficult evacuation decisions (in concert with the National Hurricane Center, the Federal Emergency Management Agency, and in some cases, elected officials). How might this occur and what might be saved? In 1997, the average error in hurricane track forecasts at $24 \mathrm{~h}$ was about 90 miles (where error is the difference between where a storm is predicted to go and where it actually goes) (M. Demaria 2000, personal communication). And $95 \%$ of such forecast errors were less than 200 miles. By inference, this means that the average 400 miles of coastline warned per storm equates to a $95 \%$ confidence level (i.e., \pm 200 miles $=400$ miles). Thus, only 1 in 20 storms will cross the coast over an area that was not warned at $24 \mathrm{~h}$. If improved forecasts can reduce the magnitude of the $95 \%$ error in miles of coastline warned by, say, $20 \%$ from 200 to 160 miles, then all else being equal, this would lead 
to a reduction in miles of the coastline warned from 400 to 320 miles ( \pm 160 miles) or a cost savings of $\$ 80$ million per storm without changing the level of risk faced by coastal communities. ${ }^{4}$

Some have suggested that instead of reducing the level of overwarning, it would be more important to increase the lead time available to the emergency management community. This argument would seem to be logical, given how long it takes to evacuate many communities and how those times are increasing. But it is impossible to effectively compare the relative benefits of reducing miles of coastline warned versus increased lead time, because the value of improved lead time has yet to be systematically studied. Back-of-theenvelope calculations in the paragraphs above used for illustrative purposes are no substitute for a rigorous empirical analysis.

The hurricane case is likely representative of a more general situation. Considerable benefits might result to public and private sector decision makers if they were to more effectively use the weather services that they already rely on simply by understanding the impacts of the forecasts in the context of the decision environment.

In the area of weather, decision makers lack some of the information necessary to make informed decisions about priorities related to prediction improvement, forecast trade-offs, and community risks. The most basic of this information is baseline knowledge of the impacts of weather and the impacts of forecasts.

\section{THE WEATHER PREDICTION ENTER-} PRISE AND THE FORECAST PROCESS. The weather prediction enterprise. The weather community is a well-developed social and political enterprise (cf. Sarewitz et al. 2000). It includes many participants with different perspectives. A diverse public demands action or the provision of useful tools and services that would inform action. But because of different values, the public does not always agree on what those tools or services might be. Participants also include policy makers looking to satisfy (or at least address) the conflicting demands made by their constituents, and a scientific community looking both to contribute to problem definition and resolution while at the same time to push the frontiers of knowledge.

The weather prediction enterprise also involves institutions. For example, the National Weather Service and its regional and local components provide

\footnotetext{
${ }^{4}$ Powell and Aberson (2001) note that forecasts of landfalling storms has not improved over the last few decades.
}

forecasts for the general public. Universities and federally funded laboratories are integral parts of the weather prediction infrastructure. Private companies provide a wide range of services ranging from infrastructure developers, to forecast providers, to research labs, to risk management, and so on. But in many cases institutional interests are arguably more narrowly defined from the publics that they are supposed to serve. For instance, the public and private sector forecast communities have had an uneasy relationship that detracts from their shared goals (USWRP 2001).

It should not be surprising that the sheer complexity of the weather prediction enterprise-participants, conflicting perspectives and values, institutions, and significant resources at stake-makes evaluation a daunting task. In fact, the existence of a weather prediction enterprise is generally not recognized as such. Yet the weather prediction enterprise is as real and pervasive as "the health care system." And as with the health care system, one can look in many directions for accountability: to scientists, the media, government regulators, politicians, special interests, and the nonexpert public. Indeed, the weather prediction enterprise is difficult for "outsiders" to penetrate because it often involves expertise that is not widely shared. The development of the enterprise in ways that contribute to societal benefits and simultaneously advance the interests of those within the community likely depends on creating those mechanisms needed by decision makers to evaluate alternative courses of action in terms of their costs and benefits. To create such mechanisms requires an understanding of the forecast process.

The forecast process. A linear model of science and society has implicitly and explicitly shaped thinking about the general connection of science and the rest of society (Pielke 1997). The model has its origins in Vannevar Bush's classic 1945 report Science: The Endless Frontier, which laid the foundation for post-war U.S. science policy. The linear model has been used as a metaphor or model to explain the relationship of science and technology to societal needs. The components of the linear model are so familiar that they are almost second nature: the model begins with basic research leading to applied research, development, and ultimately applications that lead to societal benefits.

In the 1990s a number of scholars reconsidered the Vannevar Bush framework of U.S. science policy [e.g., Sigma Xi, The Scientific Research Society 1995; National Academy of Sciences (NAS) 1995]. From this debate, Stokes (1995) presents a thoughtful discussion 
of an alternative to the linear model, that helps us move beyond the "grip" that the basic applied distinction has on how we think about science (cf. Pielke and Byerly 1998).

Stokes's alternative to the linear model is shown as a two-by-two matrix with considerations of relevance (yes or no) on one axis and considerations of advancing understanding (yes or no) on the other. In the matrix are the familiar categories of pure basic research and pure applied research. However, a third category has been added, one that is motivated both through consideration of use and a quest for fundamental understanding. Stokes calls this "Pasteur's Quadrant" and labels it "use-inspired basic research." In theory, use-inspired basic research is simply that conducted in any research program with stated societal benefit goals. The concept ought to be familiar to many in the atmospheric sciences, where consideration of the use and value of meteorological information has a long history.

Hooke and Pielke (2000) offer one interpretation of how use-inspired basic research manifests itself in the meteorological community. Weather forecasts are produced in the environment of a broader weather forecast process that includes the production of forecasts, but also communication of current weather and forecast information and the incorporation of that information in user decisions. Often, some mistakenly ascribe a linear relation to the three subprocesses, that is,

$$
\text { predict }>\text { disseminate }>\text { use }
$$

An alternative is to think of these as parallel subprocesses, with significant feedbacks and interrelations between them, in which case, one-way dissemination becomes two-way communication.

Drucker (1993, p. 54-55) has written an eloquent description of the modern organization that applies equally well applied to the weather prediction process:

\footnotetext{
"Because the organization is composed of specialists, each with his or her own narrow knowledge area, its mission must be crystal clear ... otherwise its members become confused. They will follow their specialty rather than applying it to the common task. They will each define "results" in terms of that specialty, imposing their own values on the organization."
}

Drucker continues with an apt metaphor:

"The prototype of the modern organization is the symphony orchestra. Each of 250 musicians in the orchestra is a specialist, and a high-grade one. Yet by itself the tuba doesn't make music; only the orchestra can do that. The orchestra performs only because all 250 musicians have the same score. They all subordinate their specialty to a common task."

The "common task" of the symphony orchestra is to produce good music. In the prediction process, that common task should be viewed as producing good decisions not simply good predictions. Consequently, forecasts when viewed only as products-no matter how technically good-must be in harmony with the broader prediction process in order to systematically lead to good decisions. Hooke and Pielke (2000) argue that in the case of the weather prediction enterprise, one can identify the components of the "symphony orchestra" but that the various sections are not as well in harmony as they might be, because of the missing "conductor."

Of course the choice of metaphor dictates thinking about the structure and functions of its component parts. For example, under the linear, pipeline model there would be no need for a conductor because a steady supply of "basic" research, transferred to applications, would be sufficient to lead to societal benefits. Thus, the most important tasks under this model would be to ensure the supply and quality of research and to ensure that the research can be transferred into operations. While this model has obvious appeal, it does not readily produce answers to questions such as those raised in the sidebar on page 394.

\section{AN INTEGRATED PERSPECTIVE ON WEATHER PREDICTION. If the symphony} metaphor is an accurate description of the weather prediction enterprise and its objectives, then an integrated perspective is necessary to providing public and private decision makers with information that would enhance their abilities to effectively allocate resources to weather (and within the weather enterprise itself). Integration is required in the context of effective evaluation of forecast products as well as the forecast process.

One of the most important criteria for evaluating weather forecast products is accuracy, defined as the difference between what is forecasted and what actually occurs. The more accurate a forecast is, the greater its potential value to a decision maker. Scientists have invested considerable effort in evaluating the accuracy of forecast products, and some have suggested that additional efforts are needed (Doswell and Brooks 1998). The results have shown a demonstrable longterm improvement in the ability of forecasters to pre- 
dict the weather, as measured by objective criteria (e.g., NRC 1999). According to the American Meteorological Society (1991, p. 1273):

"The notable improvement in forecast accuracy that has been achieved since the 1950s is a direct outgrowth of technological developments, basic and applied research, and the application of new knowledge and methods by weather forecasters. High-speed computers, meteorological satellites, and weather radars are tools that have played major roles in improving weather forecasts."

Of course, weather forecasts are not always reliable or usefully specific, but their accuracy (or relative inaccuracy) can be quantified by metrics that bear some relationship to the use of weather information. This track record sets weather forecasting apart from all other predictive earth sciences (Sarewitz et al. 2000).

But it is critical to recognize that an accurate forecast product is insufficient for a successful weather forecast process (Katz and Murphy 1997). ${ }^{5}$ More generally, success in any one of the three subprocesses does not necessarily result in benefits to society (e.g., Doswell and Brooks 1998; Roebber and Bosart 1996; Vislocky et al. 1995). A technically skillful forecast that is miscommunicated or misused can actually result in costs to society (Pielke 1999b). Similarly, effective communication and use of a misleading forecast can lead to decisions with undesirable outcomes. For the process to work effectively, success is necessary in all three elements of the forecast process: prediction, communication, and use. Further, success requires healthy connections between each of the elements; they cannot be considered in isolation, that is, with the tasks of prediction, communication, and use delegated to unconnected parties. Integration of evaluation methods is a necessity, such as through the development of verification metrics with a clear relationship to societal impacts.

Because the forecast process is comprised of multiple elements there is no single measure that captures the societal goodness of a forecast process. Instead, multiple measures are needed to evaluate the technical, communication, and decision dimensions of forecasts. Typically, policy makers have focused attention on the costs and benefits of forecasts in order to de-

\footnotetext{
${ }^{5}$ There are obviously situations in which a forecast in unnecessary for effective decision making. Understanding when and when not to rely on predictions is an essential aspect of the effective use of prediction.
}

termine a "bottom line" assessment of value, while social scientists have studied the communication process (e.g., warnings) and physical scientists have evaluated forecasts according to technical criteria like skill scores and "critical success indices." These different foci are important and necessary; however, the segregation of evaluation tasks has meant that no one is responsible for evaluation of the entire forecast process.

The net result is that we try to improve the system by working on its components while ignoring critical interactions visible only from a more comprehensive perspective. Consequently, when policy makers or other users of weather forecasts ask the general question "what is the value of an improved forecast?" and expect to get an aggregate answer in dollars or lives, they ask the wrong question, one based implicitly on a linear relation of research with societal benefits. They ought to instead ask, "what changes to the existing forecast process (predict, communicate, use) can we expect to lead to desired or improved outcomes?" and expect the answer to be contextual, multidimensional, and a combination of objective and subjective measures. This perspective forces the integration of knowledge that is needed to better understand the relationship of the weather forecasting enterprise and the broader society of which it is a part.

CONCLUSIONS. The nation has invested considerable resources into the development of understanding and technologies to meet the expected demands of its citizens for improved weather forecasts. Regrettably, many of the fruits of these investments have not yet been realized as useful products for decision makers, hence benefits to the nation are considerably less than they might be otherwise (e.g., NRC 2000). Examples include data from satellites and radars that are not fully or effectively used (Dabberdt et al. 1996), techniques for the manipulation of data that are understood but not used (Schlatter 2000), and knowledge of human judgment that is not incorporated into the development of useful products (Stewart et al. 1992).

At the core of such problems is a mismatch between the capability of the weather forecasting enterprise to produce scientific and technological advances, and its capability to translate those advances into useful information. A challenge facing the nation is thus to implement an improved forecasting process that takes full advantage of our continuing national investment in observations, research, and technology. Without enabling an improved forecast process the nation will not fully benefit from its ongoing investments, 
and may thus fail to meet society's growing expectations of weather prediction.

Two recommendations follow straightforwardly from the perspective offered herein:

1) The weather community should take on fully, as its responsibility, the systematic and comprehensive understanding of weather and forecast impacts. It is difficult to target scarce resources (much less argue for a greater share of those scarce resources) on the so-called "low hanging fruit" without some objective confirmation of where that fruit is. While there is almost universal recognition that such information is important, little progress has been made in systematically developing and sustaining a knowledge base of weather and forecast impacts. Superficial or short-term benefit-cost studies, often commissioned hastily by public agencies in support of annual budget requests tend to cloud rather than clarify understanding, and certainly siphon resources from the development of a more reliable and robust understanding.

2) Leaders in the weather community should seek to develop a substantive understanding and vision that wields real, not pretended, power and leads the community to work in a mutually reinforced collaboration toward common goals. ${ }^{6}$ The various parts of the weather prediction community are each members of a broader enterprise with common goals of considerable societal importance. These common goals are unlikely to be reached if the community proceeds in the balkanized fashion that has characterized it in the past-public versus private, research versus operations, satellite versus in situ, and other lines of division. Both the weather community and the broader society of which it is a part would benefit from an overarching perspective on the weather prediction enterprise and the effectiveness of its processes.

Of these two recommendations the first will be much easier to achieve than the second. Achieving the first requires a modest resource allocation, given that the infrastructure and expertise necessary to obtain knowledge of impacts largely exists (e.g., Pielke et al. 1997; USWRP 1997). Achieving the second requires a fundamental shift in the structure of the community. It requires strong and balanced leadership with

\footnotetext{
${ }^{6}$ Design and delineation of the specific structures go well beyond the scope of this paper. However, we view as a necessary first step discussion of such a vision and then acceptance of its legitimacy.
}

a greater breadth of interaction than is presently associated with institutions, agencies, and sectors of the community in the United States. But in spite of the difficulties posed by these obstacles, there is reason for optimism: societal demand for useful knowledge in return for support for the weather prediction enterprise may itself compel needed change. Of course, such change will likely be more effective and with less pain if motivated from within rather than without.

As the United States moves into the twenty-first century, the nation expects greater accuracy, timeliness, and reliability in weather forecasts, as well as an increased number of useful products (NRC 1998). In an improved forecasting process, such products could play an increasingly important role in both public and private sector decision making. Furthermore, an improved forecast process could provide expanding opportunities to better protect life and property, stimulate economic activity, enhance national competitiveness, and contribute to environmental management (NRC 1998).

Because the nation has not yet fully benefited from its weather investments, many scientists are concerned that the public, through the government, will react by reducing support for research. But this would be a mistake, and illogical from the perspective of weather forecasting as a prediction process. It would be much as if the owner of a grocery store with a backlog of bread on its shelves were to address this problem by telling farmers to stop planting wheat. The issue is not like regulating flow through a pipeline, but rather like managing numerous parallel processes to form a coherent whole-again, like trying to get a symphony orchestra to produce music. Thus, a central challenge facing the community is to identify opportunities to improve forecast processes and to recommend alternative courses of action necessary and sufficient to open the way to more effective and efficient capitalization of the considerable public-private investment in weather forecast research and technology.

A limitation more fundamental than resources is leadership. If the various forecast processes and individual enterprises are to work together like the components of a symphony orchestra, then these currently suffer from the lack of a functional "conductor." No organization or entity has embraced the collective measure of responsibility for improving forecast processes. A committee of the National Research Council has arrived at a consistent conclusion in a broad review of atmospheric research: "no one sets the priorities; no one fashions the agenda" (NRC 1998, p. 58). While many participants in the nation's fore- 
casting system agree that the process should be improved (by someone), the community has not organized itself to systematically evaluate the existing process and implement improvements. Candidate conductors, from various sectors of the community are self-evident; however, none presently command the full breadth or mutual trust needed to affect the common interests of the weather prediction enterprise. Others outside the community might take on a leadership role, such as the National Academy of Sciences, the President's Council of Advisors on Science and Technology, or even the U.S. Congress. But until someone takes or is given responsibility to better integrate the multifaceted forecast process, it is likely that a gap will continue to exist, if not broaden, between knowledge of weather forecasting and its effective use. Without recognition that it is the integrated forecast process that needs attention, and not simply improvement in forecast products, implementation of even the best-intended plans is likely to fall short of achieving the nation's potential in outcomes related to weather prediction.

ACKNOWLEDGMENTS. We thank Carey Bousquet, Stacey Applen, Mark DeMaria, Mark Powell, Bobbie Klein, and D. Jan Stewart for their contributions to this paper. Three reviewers provided useful guidance.

\section{REFERENCES}

American Meteorological Society, 1991: Weather forecasting: A policy statement of the American Meteorological Society as adopted by the Council on 13 January 1991. Bull. Amer. Meteor. Soc., 72, 1273-1276.

Changnon, S., R. A. Pielke Jr., D. Changnon, R. T. Sylves, and R. Pulwarty, 2000: Human factors explain the increased losses from weather and climate extremes. Bull. Amer. Meteor. Soc., 81, 437-442.

Dabberdt, W., and T. Schlatter, with contributions from the rest of the PDT-2 1996: Research opportunities from emerging atmospheric observing and modeling capabilities. Bull. Amer. Meteor. Soc., 77, 305-323.

Doswell, C., and H. Brooks, 1998: Budget cutting and the value of weather services. Wea. Forecasting, 13, 206-212.

Drucker, P., 1993: Post-capitalist Society. Harper Collins, 232 pp.

Emanual, K., and Coauthors, 1995: Report of the first prospectus development team of the U.S. Weather Research Program to NOAA and NSF. Bull. Amer. Meteor. Soc., 76, 1194-1208.

The H. John Heinz III Center for Science, Economics and the Environment, 1999: The Hidden Costs of
Coastal Hazards: Implications for Risk Assessment and Mitigation. Island Press, $220 \mathrm{pp}$.

Herbert, P. J., J. D. Jarrell, and M. Mayfield, 1996: The deadliest, costliest, and most intense hurricanes of this century (and other frequently requested hurricane facts). NOAA Tech. Memo. NWS TPC-I. [Available online at http://www.esig.ucar.edu/ socasp/data/tables2.html.]

Hooke, W. H., and R. A. Pielke Jr., 2000: Short-term weather prediction: An orchestra in search of a conductor. Prediction: Science, Decision Making and the Future of Nature, D. Sarewitz, R. A. Pielke Jr., and R. Byerly, (Eds.), Island Press, 61-83.

Jarrell, J. D., and M. DeMaria, 1999: An examination of strategies to reduce the size of hurricane warning areas. Preprints, 23rd Conf. on Hurricanes and Tropical Meteorology, Vol. I, Dallas, TX, Amer. Meteor. Soc., 50-53.

Katz, R., and A. Murphy, 1997: Economic Value of Weather and Climate Forecasts. Cambridge University Press, 222 pp.

Kunkel, K., R. A. Pielke Jr., and S. A. Changnon, 1999: Temporal fluctuations in weather and climate extremes that cause economic and human health impacts: A review. Bull. Amer. Meteor. Soc., 80, 10771098.

Mileti, D., 1999: Disasters by Design: A Reassessment of Natural Hazards in the United States. Joseph Henry Press, 376 pp.

National Academy of Sciences, 1995: Allocating Federal Funds for Science and Technology. National Academy Press, 108 pp.

National Research Council, 1998: The Atmospheric Sciences Entering the Twenty-First Century. National Academy Press, 384 pp.

- 1999: A Vision for the National Weather Service: Road Map of the Future. National Academy Press, $88 \mathrm{pp}$.

—, 2000: From Research to Operations in Weather Satellites and Numerical Weather Prediction: Crossing the Valley of Death. National Academy Press, $96 \mathrm{pp}$.

- Committee on Assessing the Costs of Natural Disasters, 1999: The Impacts of Natural Disasters: A Framework for Loss Estimation. National Academy Press, $80 \mathrm{pp}$.

Parrish, G., 1997: Impacts of weather on health. Center of Disease Control. [Available online at www.esig. ucar.edu/socasp/weather1/parrish.html.]

Pielke, R. A., Jr., 1997: Asking the right questions: Meteorological research and societal needs. Bull. Amer. Meteor. Soc., 78, 255-264.

-, 1999a: Hurricane forecasting. Science, 284, 1123. 
_- 1999b: Who decides? Forecasts and responsibilities in the 1997 Red River flood. Amer. Behav. Sci. Rev., 7, 83-101.

—, and M. H. Glantz, 1995: Serving science and society: Lessons from large-scale atmospheric science programs. Bull. Amer. Meteor. Soc., 76, 24452458.

— Phys. Today, 51, 42-46.

- J. Kimple, and the Sixth Prospectus Development Team, 1997: Societal aspects of weather: Report of the Sixth Prospectus Development Team of the U.S. Weather Research Program to NOAA and NSF. Bull. Amer. Meteor. Soc., 78, 867-876.

-, R. Klein, and J. Oxelson, 2001: Extreme Weather Sourcebook 2001. NCAR, NOAA, USWRP, NSF, AMS. [Available online at cires.colorado.edu/ pielke/sourcebook/index.html.]

Powell, M. D., and S. D. Aberson, 2001: Accuracy of United States tropical cyclone landfall forecasts in the Atlantic basin (1976-2000). Bull. Amer. Meteor. Soc., 82, 2749-2768.

Roebber, P. J., and L. F. Bosart, 1996: The complex relationship between forecast skill and forecast value: A real-world comparison. Wea. Forecasting, 11, 544-559.

Sarewitz, D., R. A. Pielke Jr., and R. Byerly, Eds., 2000: Prediction: Decision-Making and the Future of $\mathrm{Na}$ ture. Island Press, 405 pp.
Schlatter, T., 2000: An implementation plan for research in quantitative precipitation forecasting and data assimilation. U.S. Weather Research Program. [Available online at http://box.mmm.ucar.edu/ uswrp/implementation/DAIMPL8new900.htm.]

Sigma Xi, The Scientific Research Society, 1995: Vannevar Bush II: Science for the 21st Century. Sigma $\mathrm{Xi}, 270 \mathrm{pp}$.

Stewart, T. R., 1997: Forecast value: Descriptive decision studies. Economic Value of Weather and Climate Forecasts, R. Katz and A. Murphy, Eds., Cambridge University Press, 147-182.

— , W. R. Moninger, K. F. Heideman, and P. ReaganCirincione, 1992: Effect of improved information on the components of skill in weather forecasting. Organ. Behav. Human Decis. Proc., 53, 107-134.

Stokes, D. E., 1995: Pasteur's Quadrant: Basic Science and Technological Innovation. Brookings Institute Press, 180 pp.

USWRP, 1997: Proc. Workshop on the Social And Economic Impacts of Weather. Boulder, CO, USWRP, 139 pp.

—, 2001: Report of the USWRP workshop on the weather research needs of the private sector, December 2000. USWRP, 42 pp.

Vislocky, R. L., J. M. Fritsch, and S. N. DiRienzo, 1995: Operational omission and misuse of numerical precipitation probabilities. Bull. Amer. Meteor. Soc., 76, 49-52.

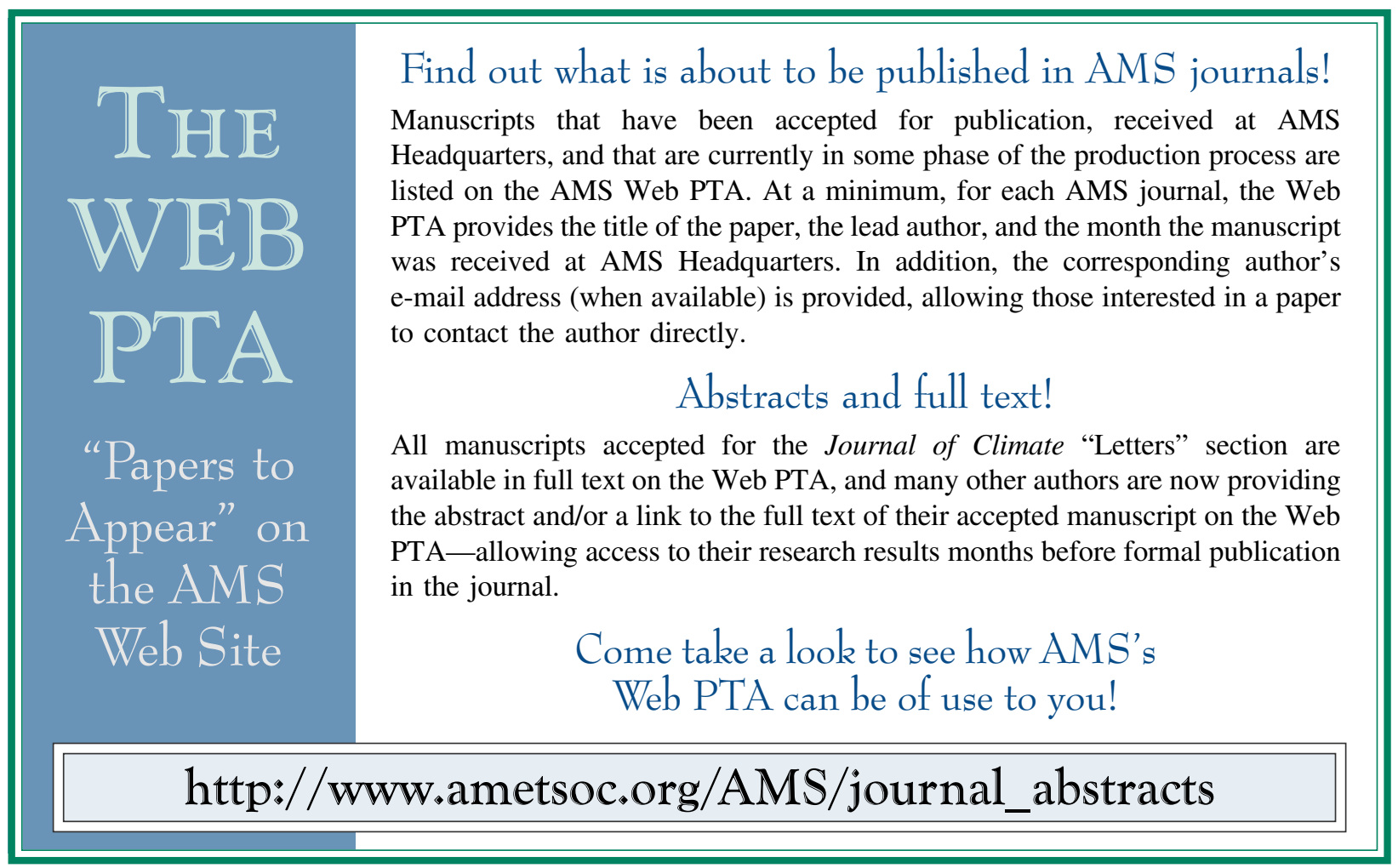

